\title{
İnsan Hareketlerinin Tanınması için Parçacık Sürü Optimizasyonu Tabanlı Topluluk Sınıflandırıcı Yöntemi
}

\author{
İlhan AYDIN*, Büşran AŞICI \\ ${ }^{1}$ Bilgisayar Mühendisliği Bölümü, Mühendislik Fakültesi, Fırat Üniversitesi, Elazığ, Türkiye \\ ${ }^{2}$ Bilgisayar Mühendisliği Bölümü, Mühendislik Fakültesi, Fırat Üniversitesi, Elazı̆̆, Türkiye \\ ${ }^{* 1}$ iaydin@ firat.edu.tr, ${ }^{2}$ busran44@gmail.com
}

Öz: İnsan hareket tespiti, teknolojinin gelişmesi ile birçok çalışmanın odak noktasıdır. Hareket tespiti çalışmalarını akıllı evler, sağlık sistemleri, izleme ve güvenlik sistemleri, oyun sektörü ve spor gibi alanlarda görebilmekteyiz. Bu çalışmamızda çoğu insanın günlük olarak sıkça yaptıkları yürüme, merdivenden çıkma, merdivenden inme, oturma, ayakta durma ve uzanma aktivitelerini tespit etmek için ivme sensörü verileri kullanılmıştır ve verilerden özellik çıkarımları yapılmıştır. Ortalama alma, karelerin ortalaması, oto korelasyon, frekans spektrumunda tepe değerlerinin ve pozisyonlarının hesaplanması gibi özellikler ivme verilerinin her ekseni için çıkarılmıştır. Birçok çalışmada ivme verileri ile çıkarılan özellikler bir sınıflandırma algoritması ile test edilir. Hareket tespiti için büyük veri kümeleri üzerinde tek bir sınıflandırıcı ile yüksek başarımın elde edilmesi çoğu zaman zordur. Uygulama zaman aralığı değiştiğinde tek bir öğrenme algoritması kullanmak kabul edilebilir bir performans sunmayabilir. Herhangi bir sınıflandırıcı, bir "m" zaman aralığında iyi sonuç verirken farklı bir zaman aralığında iyi sonuç vermeyebilir. Bu sebeple birden fazla sınıflandırıcının uygun şekilde birleştirilmesi ile daha yüksek başarımlar elde edilebilir. Topluluk sınıflandırıcıda, birkaç sınıflandırıcı birlikte son çıkışı oluşturur. Bu yüzden bu çalışmada topluluk seçim yöntemi önerilmiştir ve yöntemde parçacık sürü optimizasyonu tabanlı bir topluluk kullanılmaktadır. Çalışmamızda, sınıflandırıcılar bir araya getirilmekte ve sınıflandırma performansını en fazla arttıran en iyi sınıflandırıcı grup otomatik olarak seçilmektedir. Parçacık sürü optimizasyonu ile sınıflandırıcı kombinasyonu yapıldığında başarımın \%98'in üzerinde olduğu kanıtlanmıştır.

Anahtar kelimeler: Hareket tanıma, parçacık sürü optimizasyonu, topluluk sınıflandırma, makine öğrenmesi.

\section{Particle Swarm Optimization Based Ensemble Classifier Method for Recognizing Human Activities}

\begin{abstract}
Human motion detection is the focus of many studies with the development of technology. We can see motion detection studies in areas such as smart homes, health systems, monitoring and security systems, the game industry and sports. In this study, acceleration sensor data were used to determine the walking, go up the stairs, go down to stairs, sitting, standing and lying activities which are frequently performed by most people on a daily basis and feature extractions were made from the data Features such as averaging, mean of squares, auto correlation, and calculation of peak values and positions in the frequency spectrum are extracted for each axis of acceleration data. In many studies, properties extracted with acceleration data are tested with a classification algorithm. It is often difficult to achieve high performance with a single classifier on large datasets for motion detection. Using a single learning algorithm may not provide acceptable performance when the application time interval changes. Any classifier may work well in an "m" time range but not in a different time interval. For this reason, higher performance can be achieved by combining more than one classifier appropriately. In the community classifier, several classifiers together form the final output. Therefore, in this study, the community selection method is proposed and the method uses a community based particle swarm optimization. In our study, classifiers are brought together and the best classifier group that maximizes the classification performance is selected automatically. When the combination of particle swarm optimization and classifier is performed, the performance has been proven to be over $98 \%$.
\end{abstract}

Key words: Activity recognition, particle swarm optimization, ensemble classifier, machine learning.

\section{Giriş}

İnsan hareket tespiti, insanların aktivitelerini yorumlamak ve tanımlamak için gereklidir. Teknolojinin gelişmesi ile insan hareketleri sensörler ve aletler ile tespit edilip tanımlanmaktadır. Tanımlanan hareketler insan yaşamında faklı alanlarda kullanılabilmektedir. İzleme sistemleri, güvenlik sistemleri, oyun sektörü, sağlık sektörü, klinik uygulamaları ve spor bu alanlardan bazılarıdır [1-4]. İnsan hareket tespiti için üstesinden gelinmesi gereken konular vardır. Bu konulardan bazıları, ölçülecek niteliklerin seçilmesi, taşınabilir olma, kullanışlılık, ekonomik olarak ucuz ve erişilebilir olma, etkili sonuçlar veren özelliklerin seçimi, yeni kullanıcıları kolaylıkla

\footnotetext{
${ }^{*}$ Sorumlu yazar: iaydin @ firat.edu.tr. Yazarların ORCID Numaras1: ${ }^{1} 0000-0001-6880-4935,{ }^{2} 0000-0001-9735-4056$
} 
destekleme ve gerçek zamanlı veriler ile etkili sonuçlar elde etmedir [1]. Kişi hareket tespit sistemlerini, kullanılan sensör veya aletlerin kullanım alanlarına göre üç farklı guruba ayırabiliriz. Bunlar, giyilebilir sensörler ile oluşturulan sistemler, çevreye yerleştirilen sensörler ile oluşturulan sistemler ve giyilebilir sensörlerle çevreye yerleștirilen sensörlerin birlikte kullanıldığı sistemlerdir [5-6].

Giyilebilir sensörleri özellikle akıllı evlerde ve sağlık sistemlerinde görebiliriz [2]. Giyilebilen sensörlere örnek olarak ivme sensörü, jiroskop sensörler, mikrofon, akıllı saatler, akıllı telefonlar ve akıllı gözlükler örnek olarak verilebilir [3]. Aydin [6] insan hareketlerinin tanınması için destek vektör makinalar, yapay sinir ağları ve doğrusal ayrıștıııcı metotlarının performansını birleştiren bir yöntem önermiștir. Yin ve ark. [8] çalışmalarında, ışık, sıcaklık, mikrofon, iki eksenli ivmeölçer ve iki eksenli manyometreden oluşan beş farklı sensörü içeren giyilebilir sensör kartları kullanmışlardır. Amaçları anormal insan aktivitelerini tespit etmektir. Yin ve ark. [9], yürüme, koşma ve oturma aktivitelerini tespit etmek için birden fazla akıllı telefon ve makine öğrenmesi yöntemlerinin kullanıldığı bir çalıșma yapmıșlardır. Akıllı telefon ile ivmeölçer, jiroskop, oryantasyon ve doğrusal ivme değerlerindeki değişikleri izleyerek sınıflandırma için özellik çıkarımı yapılmıştır. Çalışmalarında kullandıkları sınıflandırma algoritmaları J48, Naif Bayes, Destek Vektör Makineleri ve ileri beslemeli yapay sinir ağı algoritmalarıdır. Sonuç olarak \%99'un üzerinde doğruluk elde etmişlerdir. Attal ve ark. [7], sağlıklı bireylerin vücutlarındaki üç farklı bölgeye ( göğüs, sağ uyluk ve sol ayak bileği) yerleștirilen atalet sensörlerinden durma, oturma, uzanma, merdivenden çıkma ayağa kalkma gibi 12 günlük aktiviteden veriler toplamışlardır. Dört denetimli ( K-En Yakın Komşu, Destek Vektör Makineleri, Denetimli Öğrenme Gauss Karışımı Modeli ve Rastgele Orman), üç denetimsiz (K- Ortalamalar, Gauss Karışım Modelleri, Gizli Markov Modeli) sınıflandırma tekniğini kullanmıșlardır. Denetimli algoritmalar arasından en iyi sonuçları (özgüllük: \%99,96) K-En Yakın Komşu algoritması, Denetimsiz algoritmalar arasından en iyi sonuçları (özgüllük: \%98,38) Gizli Markov Modeli algoritması vermiştir. Yatani ve Truong [10], yürüme ve koşma gibi aktivitelerden farklı olarak yeme, içme, konuşma ve gülme aktivitelerini belirlemek için boğaz bölgesine yerleştirilen giyilebilir akustik sensör (BodyScope) geliștirmișlerdir.

Çevreye yerleştirilen sensörlere kameralar, Kinect, akustik sensörler, basınç sensörleri, kızılötesi sensörler örnek olarak verilebilir [11-13]. Kameralar, kişi hareket tespiti için kullanılan önemli aletlerden biridir. Mirmahboub ve ark. [14], çalışmalarında, mevcut düşme tespiti yöntemlerinin çoğundan üç ana adımın ayırt edilebileceğinden bahsetmiștir. Bu adımlar, sabit bir arka planın hareketli bir ön plandan çıkarımı olan hareket bölümleme, sınıflandırmanın yapıldığı özelliklerin ön plan dizisinden çıkarılması ve önceden eğitilmesi gereken karmaşık bir yapı veya basit bir eşik değeri ile sınıflandırmanın yapılmasıdır. Düşme tespiti için önerdikleri yöntemde, sabit bakış açısındaki tek bir kamera kullanılmaktadır. Kişi siluetini iki farklı arka plan ayırma ile alan ve siluet alanından çıkarılan özellikleri, Destek Vektör Makinaları yöntemi ile sınıflandıran bir metot sunmuşlardır. Sonuç olarak yaklaşık \%4,8 hata oranı elde etmişlerdir. Khan ve ark. [15], düşme tespitinde ayak sesi sinyallerini toplamak için akustik sensörler kullanmışlardır. Bir diğer çevresel sensör ise Kinect sensörüdür. Kızılötesi kullandığı için Kinect sensörü ile derinlik görüntüleri elde edilir. Yalnızca derinlik görüntüleri ile kişi izleniminin yapılması, kişinin mahremiyetinin korunması açısından renkli kameralardan daha avantajlıdır [16]. Ayrıca az aydınlık ortamlarda (oda gibi) kişiler kolaylıkla derinlik haritalarından tespit edilebilir. Yao ve Fu [17], el hareketlerini tespit etmek için Kinect sensörünü kullanmıştır. Mastorakis ve Makis [18], Kinect sensöründen elde edilen derinlik görüntülerindeki 3B sınırlayıcı kutunun yükseklik, genișlik ve derinlik verilerinin birinci türevi olan hızdaki değișimler ile düşme tespiti yöntemi önermișlerdir. Verimli sonuçlar elde etmişlerdir. Düssme tespiti için kullandıkları hız faktörü, 3B sınırlayıcı kutunun yükseklik, derinlik ve genişlik verilerinden elde edildiğinden düşmenin tespiti için zemin koordinatlarına, başın tespit edilmesine veya kişinin kütle merkezini hesaplanmasına gerek kalmamıştır. Ancak kişi dışında hareket eden bir nesne de görüş alanı içerisinde olursa ve bu nesne de düșerse önerdikleri sistem yine düșme alarmı verebilir. Bu yüzden dezavantajlıdır. Lei Yang ve ark. [19], kiși düşme tespiti için oda ortamında Kinect sensörünü kullanmışlardır. Derinlikli görüntülerdeki hareketli bireyin silueti, arka plan çıkarımı ile elde edilmiştir. Pozisyon ve oryantasyon analizi ve belirlenmiş bazı eşik değerlere göre düşme tespiti yapılmıştır. Bazı düşme tespiti sistemlerinde giyilebilir sensörlerle çevreye yerleştirilen sensörler bir arada kullanılmıştır. Bunlara örnek olarak Kepski ve Kwolek [2, 16, 20]'in ivme ve derinlik sensörlerini birlikte kullanarak yapmış oldukları düşme tespiti çalışmaları verilebilir. Wang ve ark. [21] insan hareket tanıma için farklı teknikleri karşılaştırmış ve telefondan alınan ivme ve jiroskop sinyallerinin kullanımının başarım üzerindeki etkisini karşılaştırmıştır. İvme sensör verilerinden hareket tespitinin performansını arttırmak için dinamik doğrusal ayrıştırıcı yöntemini önermişlerdir [22]. Önerilen yöntemin var olan tekniklere göre daha iyi başarım verdiği ispatlanmıştır.

$\mathrm{Bu}$ çalışmanın amacı, insanların günlük yaşamda sıkça yapmış oldukları yürüme, merdivenden çıkma, merdivenden inme, oturma, ayakta durma ve uzanma aktivitelerini tespit etmektir. Bu amaçla parçacık sürü optimizasyonu tabanlı bir topluluk sınıflandırıcı yöntemi önerilmiştir. Büyük veri kümeleri üzerinde tek bir 
sınıflandırıcı ile yüksek başarımın elde edilmesi çoğu zaman zordur. Birden fazla sınıflandırıcının uygun şekilde birleştirilmesi ile daha yüksek başarımlar elde edilebilir. Bu çalışma kapsamında önerilen topluluk seçim yöntemi, parçacık sürü optimizasyonunu kullanarak sınıflandırma performansını en fazla arttıran en iyi sınıflandırıcı grup otomatik olarak seçilmektedir. Böylelikle insan aktivite tespiti için doğruluğun arttırılması amaçlanmıştır. Yapılan testler sonucunda etkili sonuçlar elde edilmiştir.

\section{Parçacık Sürü Optimizasyonu}

Parçacık Sürü Optimizasyonu (PSO) 1995 yılında Kennedy ve Eberhart tarafından sunulmuş olup, sürekli doğrusal olmayan fonksiyonlar için bir optimizasyon yöntemidir [23-24]. Temel prensibi kuş ve balık sürülerinin yiyecek ararken yapmış oldukları hareketlerden esinlenilmiştir. Sürü veya popülasyon düzensiz gibi görünen bir koleksiyondur. Sürüdeki her bir parçacık rastgele bir yönde hareket ediyor gibi gözükse de kümelenme eğiliminde olan hareketli bireylerdir. Kennedy yiyecek arayan kuşlar için bir "mısır tarlası vektörü” geliştirmiştir. .

Pozisyonlar ve vektörler öncelikle rastgele atanır, potansiyel çözümler aşırı uzayda uçurulur. Sonra her parçacık aşırı uzayda, en iyi pozisyonunu takip eder. Burada bireysel en iyi konumu, popülasyona göre en iyi konumu ve komşuluğa göre en iyi konumu olmak üzere üç çeşit iyi konum vardır. Her zaman adımında rastgele bir şekilde kendi en pozisyonu ve popülasyonun en iyi pozisyonuna doğru hızlanır. Parçacık Sürü Optimizasyonu adımları aşağıda verilmiştir.

Adım 1: Aşırı uzaydaki popülasyonu tanımla.

Adım 2: Bireysel parçacıkların uygunluğunu ölç.

Adım 3: Hızları önceki en iyiye ve global en iyiye ( ya da komşuluk en iyiye) göre değiştir. Hız ( $v$ ) ve konum $(x)$, Denklem 1 ve Denklem 2'ye göre güncellenir.

Adım 4: Koşula göre sonlandır.

Adım 5: Adım 2'ye git

$$
\begin{aligned}
& \mathrm{v}_{\mathrm{id}}=\mathrm{w}_{\mathrm{i}} \cdot \mathrm{v}_{\mathrm{id}}+\mathrm{c}_{1} \cdot \operatorname{rand}() \cdot\left(\mathrm{p}_{\mathrm{id}}-\mathrm{x}_{\mathrm{id}}\right)+\mathrm{c}_{2} \cdot \operatorname{rand}() \cdot\left(\mathrm{p}_{\mathrm{gd}}-\mathrm{x}_{\mathrm{id}}\right) \\
& x_{\mathrm{id}}=x_{\mathrm{id}}+v_{\mathrm{id}}
\end{aligned}
$$

Burada $v$, parçacık hızını; $x$, parçacık konumunu; d, boyutu; $c_{1}$ ve $c_{2}$ pozitif sabit değerleri; rand() rastgele fonksiyonları; $p_{\mathrm{id}}$, i. parçacığın d boyutu için şu ana kadar ki en iyi pozisyonu, $p_{\mathrm{gd}}$ ise bütün popülasyon içinde mevcut olan global en iyi pozisyonu; w ise atalet ağırlığını temsil etmektedir. Bu formülün komşuluğa göre olan halinde $p_{\text {gd }}$ yerine $p_{\text {ld }}$ yazllabilir.

Global en iyi PSO algoritmasının temel adımları Şekil 1'de gösterilmektedir.
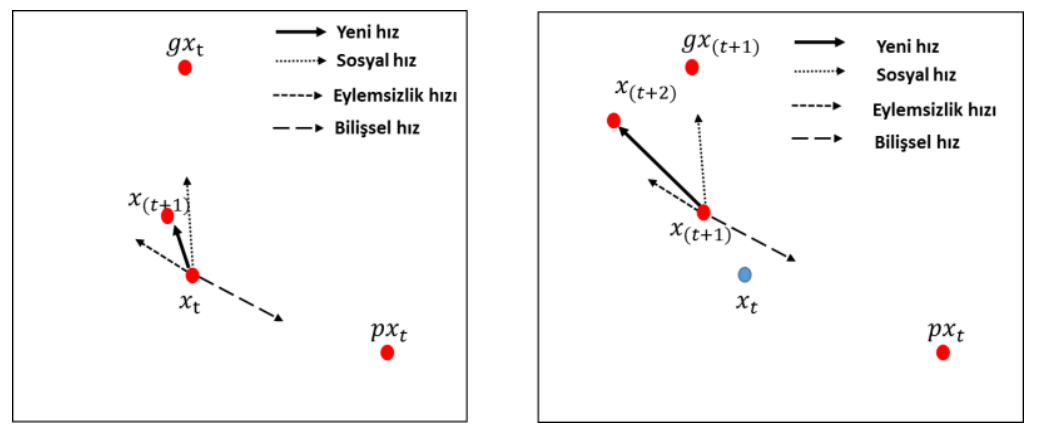

Şekil 1. Tek parçacık için hız ve konum güncellemelerinin iki boyutlu, geometrik gösterimi

Şekil 1'de parçacığın t zaman adımındaki ve $(\mathrm{t}+1)$ zaman adımındaki durumları gösterilmiştir [14]. Şekilde $x_{\mathrm{t}}$, $\mathrm{t}$ zaman anındaki pozisyonunu temsil etmektedir. Yeni pozisyon olan $x_{(\mathrm{t}+1)}$, küresel en iyi pozisyon olan $g x_{(\mathrm{t}+1)}$ 'e yaklaşmıştır. $g x_{(\mathrm{t}+1)}$, sürü tarafından bulunan en iyi pozisyondur. $p x_{\mathrm{t}}$ ise parçacık tarafından başlangıçtan beri erişilmiş en iyi pozisyondur. Bir sonraki zaman adımında kişisel en iyi pozisyonu Denklem 3 'teki gibi hesaplanır. 
$p x_{(\mathrm{t}+1)}=\left\{\begin{array}{c}p x_{\mathrm{t}}, f\left(x_{(\mathrm{t}+1)}\right) \geq f\left(p x_{\mathrm{t}}\right) \\ x_{(\mathrm{t}+1)}, f\left(x_{(\mathrm{t}+1)}\right)<f\left(p x_{\mathrm{t}}\right)\end{array}\right.$

\section{Hareket Tanıma için Önerilen Topluluk Sınıflandırıcı Yöntemi}

Büyük veri kümeleri üzerinde tek bir sınıflandırıcı ile yüksek başarımın elde edilmesi çoğu zaman zordur. Birden fazla sınıflandırıcının uygun şekilde birleştirilmesi ile daha yüksek başarımlar elde edilebilir. Bu çalışma kapsamında önerilen topluluk seçim yöntemi parçacık sürü optimizasyonu tabanlı bir topluluk kullanarak bir araya getirilmekte ve sinıflandırma performansını en fazla arttıran en iyi sınıflandırıcı grup otomatik olarak seçilmektedir. Önerilen yöntemin blok şeması Şekil 2'de verilmiştir.

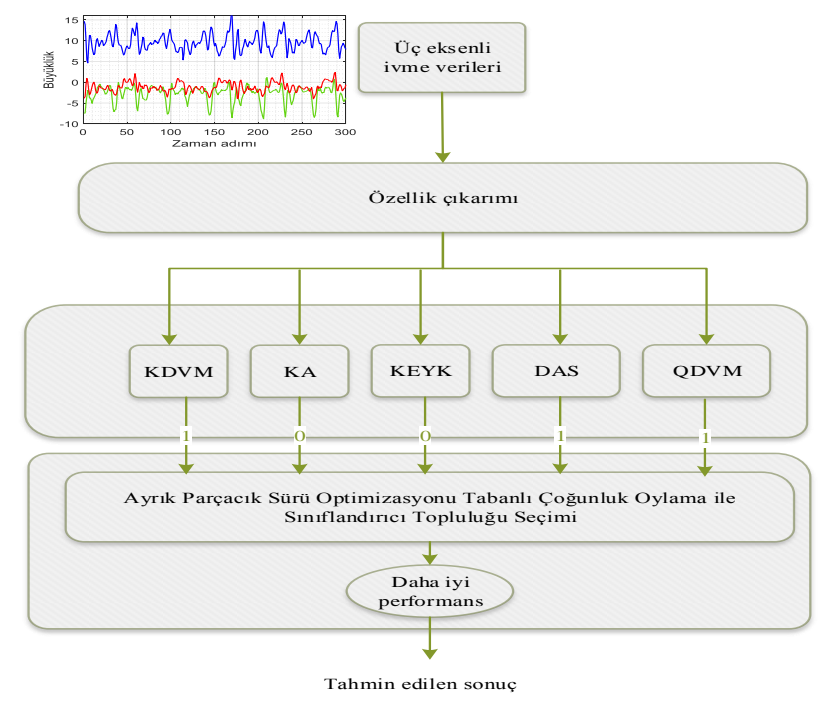

Şekil 2. Parçacık sürü optimizasyonu tabanlı topluluk sınıflandırıcı

Şekil 2'de ilk olarak üç eksenli ivme verileri alınarak özellik çıkarımı yapılmaktadır. Özellik çıkarımında 66 adet özellik çıkarılmaktadır. Her bir ivme ekseni için çıkarılan özellikler, ortalama alma, karelerin ortalaması, oto korelasyon, frekans spektrumunda tepe değerlerinin ve pozisyonlarının hesaplanmasıdır. Özellik çıkarımında iki farklı hareket için frekans spektrumunda tepe değerleri Şekil 3 'te verilmiştir.

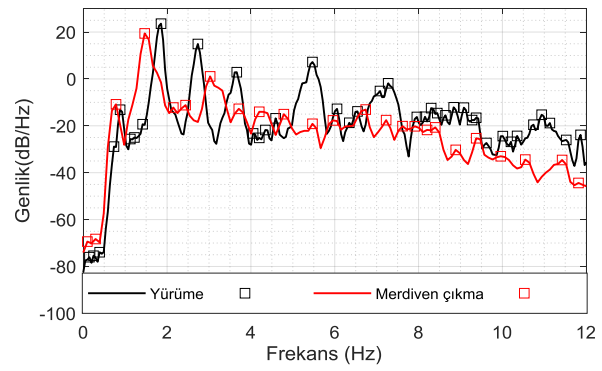

Şekil 3. Yürüme ve merdiven çıkma hareketleri için frekans spektrumları

Şekil 3’te de görüldüğü gibi yürüme ve merdiven çıkma hareketlerinde hem genlikler hem de oluşan tepe değerlerinin pozisyonları farklıdır. Dolayısıyla iki bilgi de özellik çıkarımında kullanılmaktadır. Özellik çıkarımından sonra elde edilen eğitim kümesi her bir sınıflandırıcıya verilerek eğitilmiş modeller elde edilmektedir. Bu modellerin seçimi için MATLAB Classification Learner aracı kullanılmıştır. Bu araç aynı veri için çoklu sınıflandırma yöntemlerini kullanarak verileri eğitmektedir. Eğitimde çapraz doğrulama kullanılmakta olup önerilen sınıflandırıcıların performansı eğitimde kullanılmayan veriler ile ölçülmektedir. Bu araç kullanılarak 
ilgili eğitim kümesi farklı sınıflandırıcılar ile sınıflandırma performansları ölçülmüş ve bunlar içerisinde Kübik Destek Vektör Makineler (KDVM), Karar Ağacı (KA), K-En Yakın Komşu sınıflandırıcı (KEYK), Doğrusal ayırt edici sınıflandırma (DAS) ve Quadratik Destek Vektör Makinalar (QDVM) en yüksek performansı veren sınıflandırıcılar olduğu için seçilmiştir.

Parçacık sürü optimizasyonun orijinal versiyonu reel sayılar üzerinde çalışarak reel uzayda işlem yapar. Hem hız hem de pozisyon güncellemesi reel sayılar üzerinde verilen aralıkta yapılır. Burada önerilen yöntem farklı sınıflandırıcılar içerisinde hangi kombinasyondan sınıflandırıcı seçilirse daha iyi bir sınıflandırma performansı elde edileceğidir. Bu yüzden ayrık parçacık sürü optimizasyonu önerilmiştir. Ayrık parçacık sürü optimizasyonundan her parçacık, Denklem (4)'teki gibi kodlanmaktadır.

$X(i)=\left(x_{\mathrm{i}, 1}, x_{i, 2}, \ldots, x_{\mathrm{i}, \mathrm{n}}\right)$

Denklemde $x_{\mathrm{i}, \mathrm{j}}, 0$ ile 1 değerlerinden birini alır. Parçacık sayısı i=1, 2, .., N ile gösterilmektedir. Her parçacığın uzunluğu (n) topluluk sınıflandırıcı sayısıdır. Bir parçacığın her bir biti bir sınıflandırıcıya karşılık gelir ve eğer 1 ise topluluk sınıflandırıcıda etkisinin olacağı ve 0 ise herhangi bir etkisinin olmayacağını ifade eder. Elimizde 6 sınıflandırıcı ve 3 parçacık olduğu varsayılırsa kodlama Tablo 1'deki gibi gösterilebilir.

Tablo 1. Altı sınıflandırıcı için üç parçacıklı parçacık sürü optimizasyon kodlaması

\begin{tabular}{|c|c|c|c|c|c|c|}
\cline { 2 - 7 } \multicolumn{1}{c|}{} & S1 & S2 & S3 & S4 & S5 & S6 \\
\hline $\mathbf{X}(\mathbf{1})$ & 1 & 0 & 1 & 0 & 1 & 1 \\
\hline $\mathbf{X}(\mathbf{2})$ & 0 & 1 & 1 & 1 & 0 & 0 \\
\hline $\mathbf{X}(3)$ & 1 & 0 & 0 & 0 & 1 & 1 \\
\hline
\end{tabular}

Tablo 1'de X(1) parçacığında S1, S3, S5 ve S6 sınıflandırıcıları topluluk sınıflandırma için ağırlıklı oylamada olacaktır. Çünkü kodlamada sadece bu sınıflandırıcılar 1 değerini almıştır. Başlangıçta parçacıkların pozisyonları Denklem (5)'teki gibi elde edilmektedir.

$x_{i, j}=\left\{\begin{array}{lr}1, & \text { Ĕger } r \geq 0.5 \\ 0, & \text { Diğger durumlarda }\end{array}\right.$

Denklem (5)'te r, 0 ile 1 aralığında rastgele olarak üretilmiş tek düze bir reel sayıdır. Her pozisyon vektörü bir hız vektörü ile ilişkili olup bu vektör $V(i)=\left(v_{\mathrm{i}, 1}, v_{i, 2}, \ldots, v_{\mathrm{i}, \mathrm{n}}\right)$ ile verilmektedir. $X(i)$ parçacığındaki her bir $x_{\mathrm{i}, \mathrm{j}}$ boyutu $V(i)$ 'deki $v_{\mathrm{i}, \mathrm{j}}$ vektörüne bağlı olarak değişir. Popülasyonda i. parçacı̆̆ın hızı olan $V(i)$ 'nin her boyutu $v_{\mathrm{i}, \mathrm{d}}$, Denklem (6)'ya göre güncellenir.

$v_{i, d}=\psi * v_{i, j}+r_{1}\left(p b_{i, j}-x_{i, j}\right)+r_{2}\left(g b_{j}-x_{i, j}\right)$

Denklem (6)'da $\psi(0<\psi<1)$ atalet momentini, $r_{1}$ bilişsel ölçekleme ve $r_{2}$ sosyal ölçekleme parametresini göstermektedir. Denklemde $p b_{i, j}$, i. parçacı̆̆ın j boyutu için şu ana kadar ki en iyi pozisyonu, $g b_{j}$ ise bütün popülasyon içinde $\mathrm{j}$. boyut için global en iyiyi gösterir. Hız güncellemesi yapıldıktan sonra normalde sürekli uzayda çalışan parçacık sürü optimizasyonunda hız ve önceki konum toplanarak yeni pozisyon bulunmaktaydı. Fakat ayrık zamanlı parçacık sürü optimizasyonunda bu işlem Denklem (7)'deki gibi yapılmaktadır.

$x_{i, j}=\left\{\begin{array}{l}1, \quad \text { Ĕ } \operatorname{er~} r \geq \xi\left(v_{i, j}\right) \\ 0, \quad \text { Diğer durumlarda }\end{array}\right.$

Denklem 7'de r, [0,1) aralığında üretilen rastgele bir sayıyı gösterirken $\xi\left(v_{i, j}\right)$ ise Denklem (8)'e göre hesaplanır.

$\xi\left(v_{i, j}\right)=\frac{1}{1+\exp \left(-v_{i, j}\right)}$ 
Denklem 8'de hız pozitif ve büyük değer olursa hesaplanan değer 1'e yakın çıktığından ilgili bitin bir olma olasılığı yükselir. Eğer hız negatif ve büyük bir değer ise hesaplanan ifade 0'a çok yakın olduğu için parçacığın ilgili pozisyonundaki bitin sıfır olma olasılığı yükselir.

Parçacık sürü optimizasyonun amaç fonksiyonu ise her bir birey için seçilen sınıflandırıcılar ile çoğunluklu oylamaya göre doğru sınıflandırılan örnek sayısının toplam örnek sayısına bölümüdür. Bu aynı zamanda topluluk sınıflandırıcısının doğruluk oranı olarak da söylenebilir. Uygulama zaman aralığı değiştiğinde tek bir öğrenme algoritması kullanmak kabul edilebilir bir performans sunmayabilir. Herhangi bir sınıflandırıcı bir m zaman aralığında iyi sonuç verirken farklı bir zaman aralığında iyi sonuç vermeyebilir. Topluluk sınıflandırıcıda, birkaç sınıflandırıcı birlikte son çıkışı oluşturur. Önerilen parçacık sürü optimizasyonu tabanlı yöntem çoğunluk oylamaya göre bir test örneğinin sınıfını belirler. İki sınıflı bir problem için 5 sınıflandırıcının çoğunluk oylamaya göre çıkışı Tablo 2'de verilmiştir.

Tablo 2. Çoğunluk oylama ile sınıflandırma

\begin{tabular}{|c|c|c|c|c|c|c|}
\hline Örnek No & S1 & S2 & S3 & S4 & S5 & Sinıf Etiketi \\
\hline 1 & 1 & 1 & 2 & 2 & 1 & 1 \\
\hline 2 & 1 & 1 & 1 & 2 & 1 & 1 \\
\hline 3 & 2 & 2 & 1 & 2 & 2 & 2 \\
\hline 4 & 1 & 2 & 1 & 1 & 1 & 1 \\
\hline
\end{tabular}

Tablo 2'de birinci örnek için S1, S2 ve S5 sınıflandırıcıları 1 değerini verdiği için sonuç 1 olarak verilmiş̧tir. Diğer örnekler de benzer şekilde sonuç vermektedir.

\section{Uygulama Sonuçları}

İnsan hareket tanıma için önerilen yöntem HAR veri kümesi olarak bilinen bir veri seti üzerinde uygulanmıştır [25]. Kullanılan veri seti 30 farklı kişiye ait 6 farklı hareketi içermektedir. Her bir hareket için ivme verileri $50 \mathrm{~Hz}$ örnekleme frekansı ile 10 saniye kaydedilmiştir. Üç eksenli ivme sensörünün her bir sinyali 128 örnek içermekte olup; yürüme, merdiven çıkma, merdiven inme, oturma, ayakta durma ve uzanma hareketlerini içermektedir. Her hareket için üç eksenli ivme verileri Şekil 4'te verilmiştir.
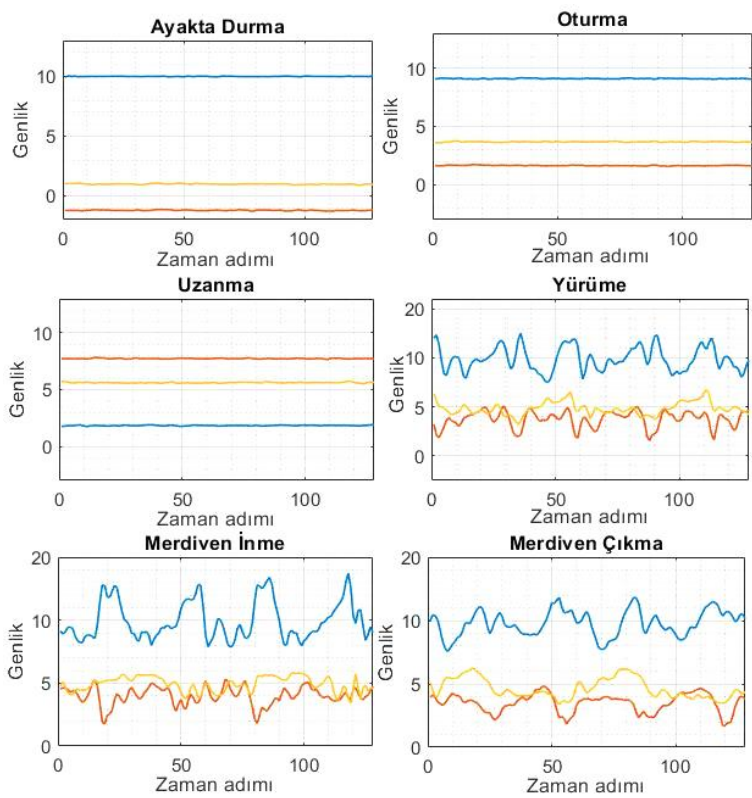

Şekil 4. Farklı hareketler için üç eksen ivme sinyalleri

Şekil 4'ten gösterildiği gibi farklı hareketlerin sinyalleri birbirine benzer şekilde bir davranış sergilemektedir. Bu yüzden veri üzerinde ön işleme yapılarak toplam 66 özellik çıkarılmıştır. Elde edilen özellikler Tablo 3'te gösterilmiştir. 
Tablo 3. İvme verilerinden elde edilen özellikler

\begin{tabular}{|l|c|c|c|}
\hline \multirow{2}{*}{ Elde edilen özellikler } & \multicolumn{2}{|c|}{ İvme sensörü eksenleri } \\
\cline { 2 - 4 } & $\mathbf{X}$ & $\mathbf{Y}$ & $\mathbf{Z}$ \\
\hline Ortalama & 1 & 1 & 1 \\
\hline Karelerin ortalamasının karekökü & 1 & 1 & 1 \\
\hline Kovaryans özellikleri & 3 & 3 & 3 \\
\hline Frekans spektrumu tepe noktaları & 6 & 6 & 6 \\
\hline Frekans spektrumu tepe noktalarının pozisyonu & 6 & 6 & 6 \\
\hline Frekans güç bandı & 5 & 5 & 5 \\
\hline
\end{tabular}

Tablo 3 'te toplamda 6 adet özellik her bir ivme ekseninden elde edilmiştir. Her bir özellik türü ve eksen için elde edilen özellik sayısı ilgili hücrelerde sayısal olarak verilmiştir. Dolayısıyla toplamda 66 adet özellik elde edilmiştir. Veri kümesi toplamda 10,300 adet örnekten oluşmakta olup sınıflandırma işleminde 10 noktalı çapraz doğrulama uygulanmıştır. Sınıflandırma sonucu beş sınıflandırıcı için elde edilen karmaşıklık matrisi Şekil 5'te verilmiştir. Şekil 5'te gösterilen satır ve sütunlardaki rakamlar aktiviteleri temsil etmektedir (1: Yürüme, 2: Merdiven Çıkma, 3: Merdiven İnme, 4: Oturma, 5: Ayakta Durma, 6: Uzanma).

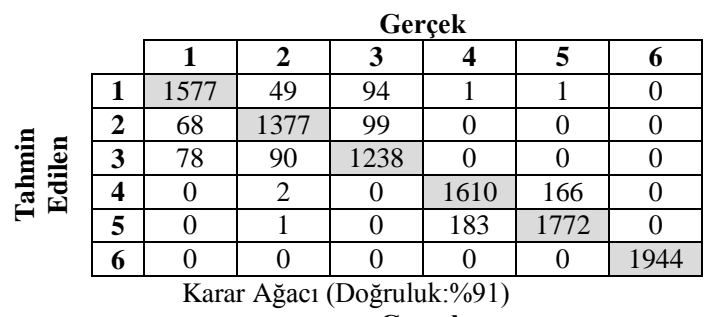

Gerçek

䍃

Kubik Destek Vektör Makinalar (Doğruluk: \%94.0)

\begin{tabular}{|c|c|c|c|c|c|c|c|}
\hline & \multicolumn{6}{|c|}{ Gerçek } \\
\hline & & 1 & 1 & 1 & 1 & 1 & 1 \\
\hline \multirow{6}{*}{ 䓃 } & 1 & 1665 & 15 & 42 & 0 & 0 & 0 \\
\hline & 2 & 17 & 1504 & 23 & 1 & 0 & 0 \\
\hline & 3 & 41 & 51 & 1314 & 0 & 0 & 0 \\
\hline & 4 & 0 & 1 & 0 & 1619 & 158 & 31 \\
\hline & 5 & 0 & 0 & 1 & 219 & 1686 & 1 \\
\hline & 6 & 0 & 0 & 0 & 0 & 0 & 1944 \\
\hline
\end{tabular}

Quadratik Destek Vektör Makinalar (Doğruluk oranı: \%94.5)

\begin{tabular}{|c|c|c|c|c|c|c|c|}
\hline & \multicolumn{6}{|c|}{ Gerçek } \\
\hline & & 1 & 2 & 3 & 4 & 5 & 6 \\
\hline \multirow{6}{*}{ 兽 } & 1 & 1698 & 4 & 20 & 0 & 0 & 0 \\
\hline & 2 & 12 & 1509 & 23 & 0 & 0 & 0 \\
\hline & 3 & 17 & 30 & 1359 & 0 & 0 & 0 \\
\hline & 4 & 1 & 1 & 0 & 1500 & 273 & 3 \\
\hline & 5 & 0 & 1 & 0 & 271 & 1634 & 0 \\
\hline & 6 & 0 & 3 & 1 & 6 & 0 & 1944 \\
\hline
\end{tabular}

Doğrusal Ayırt Edici Sınıflandırma (Doğruluk: \%93.5)

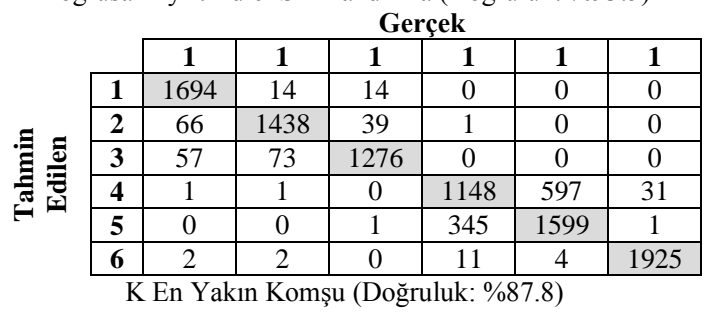

Sinıf Etiketleri:

1: Yürüme

2: Merdiven çıkma

3: Merdivenden inme

4: Oturma

5: Ayakta durma

6: Uzanma

Şekil 5. Beş farklı sınıflandırıcının karmşıklık matrisi

Şekil 5'e göre en iyi doğruluk oranı, Quadratik DVM ile elde edilmiştir. Karar ağacında maksimum bölme sayısı 100 olarak seçilmiş ve bölme kriteri için Gri indeks kullanılmıştır. Karesel destek vektör makinası için çekirdek fonksiyonu Quadratik seçilmiştir. Çoklu sınıflandırma için birine karşı diğeri seçilmiştir. Kübik Destek Vektör Makinasında çekirdek fonksiyonu kübik seçilmiş olup çekirdek ölçeği otomatik seçilmiş ve çoklu sınıflandırma birine karşı diğeri yöntemine göre yapılmıştır. Ağırlıklı en yakın komşu algoritmasına göre mesafe fonksiyonu Öklid seçilmiş ve k değeri 10 olarak alınmıştır.

Birden fazla sınıflandırıcının uygun şekilde birleştirilmesi ile daha yüksek başarımlar elde edilebileceğinden, tek bir sınıflandırıcı yerine en iyi performansı veren beş sınıflandırıcı seçilmiştir. Seçtiğimiz beş sınıflandırıcının performanslarını çoğunluk oylama ile birleştirmek için parçacık sürü optimizasyonu tabanlı bir yöntem seçilmiştir. Amaç en iyi kombinasyonu sağlayan sınıflandırıcıları seçerek hareket tanıma performansını yükseltmektir. Parçacık sürü optimizasyonun parametreleri Tablo 4 'te verilmiş̧tir.

Tablo 4. Ayrık parçacık sürü optimizasyonun parametreleri 


\begin{tabular}{|l|l|}
\hline Parametre & Değer \\
\hline Popülasyon Boyutu & 15 \\
\hline Adım Sayısı & 50 \\
\hline $\mathrm{C}_{1}$ & 1.04 \\
\hline $\mathrm{C}_{2}$ & 1.04 \\
\hline $\mathrm{W}$ & 0.1 \\
\hline Parçacık boyutu & 5 \\
\hline
\end{tabular}

Parçacık sürü optimizasyonunda her bir parçacık 5 bit ile ifade edilmektedir. Bir sınıflandırıcı çoğunluk oylamada kullanılacaksa ilgili parçacığın biti 1, kullanılmayacaksa 0 seçilir. Şekil 6'da parçacık sürü optimizasyonunun 40 yineleme boyunca amaç fonksiyonu gösterilmiştir.

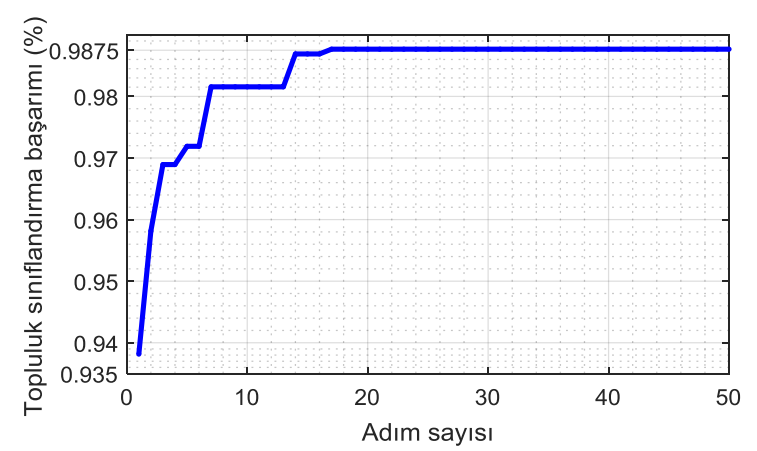

Şekil 6. Parçacık sürü optimizasyonun

Şekil 6'da gösterildiği gibi parçacık sürü optimizasyonu ile sınıflandırıcı kombinasyonu yapıldığında başarımın \%98'in üzerinde olduğu görülmektedir. Tablo 5 'te ayrık parçacık optimizasyonu ve çoğunluk oylama yöntemine göre elde edilen karmaşıklık matrisi verilmiştir.

Tablo 5. Önerilen yönteminin karmaşıklık matrisi

\begin{tabular}{|l|l|l|l|l|l|l|}
\hline & $\mathbf{1}$ & $\mathbf{2}$ & $\mathbf{3}$ & $\mathbf{4}$ & $\mathbf{5}$ & $\mathbf{6}$ \\
\hline $\mathbf{1}$ & 1717 & 1 & 4 & 0 & 0 & 0 \\
\hline $\mathbf{2}$ & 9 & 1533 & 2 & 0 & 0 & 0 \\
\hline $\mathbf{3}$ & 32 & 48 & 1326 & 0 & 0 & 0 \\
\hline $\mathbf{4}$ & 0 & 0 & 0 & 1748 & 30 & 0 \\
\hline $\mathbf{5}$ & 0 & 0 & 0 & 1 & 1905 & 0 \\
\hline $\mathbf{6}$ & 0 & 0 & 0 & 0 & 0 & 1944 \\
\hline
\end{tabular}

Tablo 5'e göre parçacık sürü optimizasyonu karar ağacı, karesel destek vektör makinalar ve doğrusal ayırt edici sınıflandırıcıları birleştirerek en iyi performansı elde etmiştir. Sınıflandırma başarımlarını ölçmek için F1, geri çağırma, keskinlik parametreleri ile birlikte doğruluk oranı kullanılmıştır. Şekil 7'de her bir durum için bu sonuçlar verilmiştir.
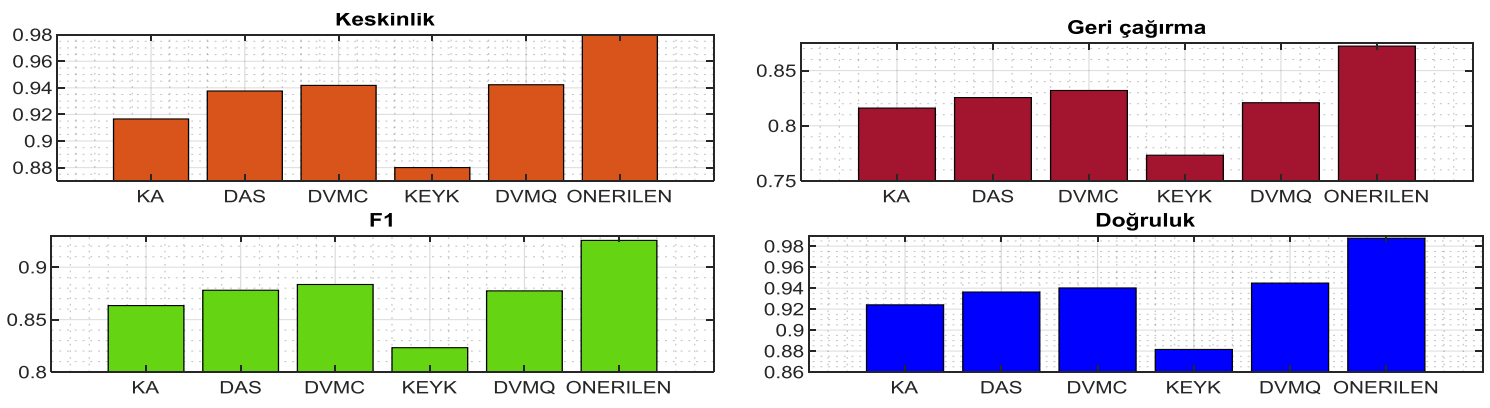

Şekil 7. Farklı performans ölçümlerine göre algoritmaların başarım oranları 
Şekil 7'de de görüldüğü gibi farklı başarım ölçümleri göz önüne alındığında önerilen yöntemin daha iyi sonuçlar verdiği görülmektedir. Birden çok sınıflandırma yönteminin birleştirilmesi ve buna göre uygun olanların kombinasyonu ile yapılan sınıflandırma işlemi oldukça yüksek başarımlar vermektedir.

Önerilen yöntemin sonuçları literatürde hareket tanıma için geliştirilen diğer teknikler ile karşılaştırılmıştır. Bu amaçla aynı veri kümesi üzerinde ivme, jiroskop ve diğer ekstra sensörlerden elde edilen özellikleri kullanan çalışmalar seçilmiştir. Karşılaştırma sonuçlarında kullanılan sensörler, özellik çıkarımı ve başarım oranları verilmiştir. Karşılaştırma sonuçları Tablo 6’da verilmiştir.

Tablo 6. Önerilen yöntemin farklı yöntemler ile karşılaştırma sonuçları

\begin{tabular}{|l|l|l|l|l|}
\hline Referans & $\begin{array}{l}\text { Kullanılan } \\
\text { sensörler }\end{array}$ & Özellik çıkarımı & $\begin{array}{l}\text { Doğruluk } \\
\text { oranı (\%) }\end{array}$ \\
\hline$[6]$ & Üç eksen ivme & Zaman ve frekans domeni özellikleri & Çoklu sınıflandırma \\
\hline$[21]$ & Jiroskop ve ivme & $\begin{array}{l}\text { Zaman ve frekans özellikleri, temel bileşen tabanlı } \\
\text { özellik seçimi }\end{array}$ & Bayes sınıflandırıcı \\
\hline$[22]$ & Üç eksen ivme & Zaman domeninde istatistiksel özellikler & Dinamik doğrusal ayrıştırıcı & 92.86 \\
\hline$[26]$ & Jiroskop ve ivme & $\begin{array}{l}\text { Gradyan histogramı ve merkezi Fourier } \\
\text { tanımlayıcıları }\end{array}$ & Destek vektör makinalar & 92.67 \\
\hline $\begin{array}{l}\text { Önerilen } \\
\text { Yöntem }\end{array}$ & Üç eksen ivme & Zaman ve frekans domeni özellikleri & $\begin{array}{l}\text { PSO tabanlı topluluk } \\
\text { sınıflandırıcı }\end{array}$ & $\mathbf{9 8 . 7 7}$ \\
\hline
\end{tabular}

Tablo 6'da jiroskop ve ivme sensörleri kullanıldığında elde edilen sonuçlar listelenmiştir. Önerilen yöntemler aynı veri kümesi üzerinde uygulanmıştır. Önerilen çalışmada kullanılan veri seti 10300 örnekten oluşmaktadır. Fakat bazı çalışmalarda veri kümesi boyutu daha düşük tutulmuştur. Tablo 6'da verilen ilk çalışmada farklı sınıflandırma yöntemleri birleştirilerek elde edilen özelliklere göre sınıflandırma başarımı arttırılmaya çalışılmıştır. Wang ve ark. [21] tarafından sunulan çalışmada ivme ve jiroskop sinyallerinden özellik çıkarımı yapılmış ve iki bilgi birleştirilerek hareket tanıma başarımı arttırılmaya çalışılmıştır. Chen ve ark. [22]'nın sunduğu çalışmada zaman domeninde bazı istatistiksel özellikler çıkarılmıştır. Temel katkı noktası ise dinamik doğrusal ayrıştırıcı tarafında yapılmıştır. Jain ve Kanhangad [26] önerdikleri çalışmada jiroskop ve ivme sinyallerinden tek boyutlu gradyan histogramı ve merkezi Fourier tanımlayıcıları ile özellikler elde etmişlerdir. Elde edilen özellikler destek vektör makinalar ile sınıflandırılmıştır. Tablo 6'da verilen sonuçlar karşılaştırıldığında çoklu sınıflandırıcıların en uygun biçimde birleştirilmesi toplam hareket tespit performansını önemli ölçüde arttırmaktadır.

\section{Sonuçlar}

Sensör tabanlı insan hareketlerini tanımak, insanların sağlıklı olup olmadığını izleme ve sağlıklı yaşam süresini iyileştirme vaadiyle çok sayıda örüntü tanıma araştırmacısının ilgi alanı olmuştur. Bu hedefler göz önüne alındığında, akıllı ortamlar çok sık talep edilen uygulamaların geliştirilmesi için önem arz etmektedir. Bu nedenle, akıllı ortamlar düşük sensör bilgisini kullanarak olay odaklı bir sistem yardımıyla kullanıcıların aktivitelerini sürekli olarak gözlemlenmesini gerektirir. Bu çalışmada insan hareketlerinin tanınması için ivme sensör bilgilerinden zaman ve frekans domeninde farklı özellikler elde edilmiştir. Elde edilen özellikler bir topluluk sınıflandırıcı ile değerlendirilerek arızaların belirlenmesi amaçlanmıştır. Sınıflandırma aşamasında tek bir sınıflandırıcı kullanmak yerine beş sınıflandırıcıdan en uygun olanlar parçacık sürü optimizasyonu ile seçilerek sonuçları birleştirilmiştir. Önerilen yöntemin temel avantajı herhangi bir sınıflandırıcının yanlış olarak sınıflandırdığı bir hareket eğer çoğunluk tarafından doğru sınıflandırılmış ise bu hareketin doğru sınıflandırılmasının sağlanmasıdır. Topluluk sınıflandırıcı olarak ifade edilen sistemde hangi makine öğrenmesi yöntemlerinin seçileceği yapılan testeler sonucunda belirlenmiştir. Bu amaçla Matlab'da bulunan sınıflandırıcı eğitim aracı kullanılmış ve en yüksek başarımı veren beş sınıflandırıcının sonuçları birleştirilmiştir. Bu aşamada parçacık sürü optimizasyonu ile bu sınıflandırıcılar içerisinde uygun olanların sonuçlarının birleştirilmesi sağlanmıştır. Elde edilen sonuçlar değerlendirildiğinde topluluk sınıflandırıcı ve parçacık sürü optimizasyonu kullanıldığında oldukça iyi sonuçların elde edildiği görülmektedir. 


\section{Kaynaklar}

[1] Wong MS, Lo KH, Wong WY. Clinical Applications of Sensors for Human Posture and Movement Analysis: A Review. Prosthetics and Orthotics International 2007; 31(1): 62-75.

[2] Kwolek B, Kepski M. Human fall detection on embedded platform using depth maps and wireless accelerometer. Computer Methods and Programs in Biomedicine 2014; 117(3): 489-501.

[3] Siddiqi MH, Ali R, Rana MS, Hong EK, Kim ES, Lee S. Video-based human activity recognition using multilevel wavelet decomposition and stepwise linear discriminant analysis. Sensors 2014; 14: 6370-6392.

[4] Shih HC. A survey of content-aware video analysis for sports. IEEE Transactions on Circuits and Systems for Video Technology 2017; 28(5), 1212-1231.

[5] Lara OD, Labrador MA. A Survey on Human Activity Recognition using Wearable Sensors. IEEE Communications Surveys \& Tutorials 2013; 15(3): 1192-1209.

[6] Aydin I. Fuzzy Integral and Cuckoo Search Based Classifier Fusion for Human Action Recognition. Advances in Electrical and Computer Engineering 2018; 18(1): 3-11.

[7] Attal F, Mohammed S, Dedabrishvili M, Chamroukh Fi, Oukhellou L, Amirat Y. Physical Human Activity Recognition Using Wearable Sensors. Sensors 2015; 15(12): 31314-31338.

[8] Yin J, Yang Q, Pan JJ. Sensor-Based Abnormal Human-Activity Detection. IEEE Transactions on Knowledge and Data Engineering 2008; 20(8): 1082-1090.

[9] Yin X, Shen W, Samarabandu J, Wang X. Human activity detection based on multiple smart phone sensors and machine learning algorithms. 2015 IEEE 19th International Conference on Computer Supported Cooperative Work in Design (CSCWD); 2015; Calabria. 582-587.

[10] Yatani K, Truang KN. BodyScope: A wearable acoustic sensor for activity recognition. Proceedings of the 2012 ACM Conference on Ubiquitous Computing. Pittsburgh, Pennsylvania: Association for Computing Machinery, 2012; 341-350.

[11] Huang P, Hsu LP. Development of a wearable biomedical health-care system. 2005 IEEE/RSJ International Conference on Intelligent Robots and Systems; 2005. 1760-1765.

[12] Cornacchia M, Ozcan K, Zheng Y, Velipasalar S. A Survey on Activity Detection and Classification Using Wearable Sensors. IEEE Sensors Journal 2017; 17(2): 386-403.

[13] Zawar HMS. Different Approaches for Human Activity Recognition- A Surway. CoRR 2019; abs/1906.05074.

[14] Mirmahboub B, Samavi S, Karimi N, Shirani S. Automatic Monocular System for Human Fall Detection Based on Variations in Silhouette Area. IEEE Transactions on Biomedical Engineering 2013; 60(2): 427-436.

[15] Khan MS, Yu M, Feng P, Wang L, Chambers J. An unsupervised acoustic fall detection system using source separation for sound interference suppression. Signal Processing 2015; 110: 199-210.

[16] Kwolek B, Kepski M. Fuzzy inference-based fall detection using kinect and body-worn accelerometer. Applied Soft Computing 2016; 40: 305-318.

[17] Yao Y, Fu Y. Contour Model-Based Hand-Gesture Recognition Using the Kinect Sensor. IEEE Transactions on Circuits and Systems for Video Technology 2014; 24(11): 1935-1944.

[18] Mastorakis G, Makris D. Fall detection system using Kinect's infrared sensor. Journal of Real-Time Image Processing 2014; 9(4): 635-646.

[19] Yang L, Ren Y, Zh ang W. 3D depth image analysis for indoor fall detection of elderly people. Digital Communications and Networks 2016; 2: 24-34.

[20] Kepski M, Kwolek B. Embedded system for fall detection using body-worn accelerometer and depth sensor. 2015 IEEE 8th International Conference on Intelligent Data Acquisition and Advanced Computing Systems: Technology and Applications (IDAACS); 2015; Warsaw. 755-759.

[21] Wang A, Chen G, Yang J, Zhao S, Chang CY. A comparative study on human activity recognition using inertial sensors in a smartphone. IEEE Sensors Journal 2016; 16(11): 4566-4578.

[22] Chen YP, Yang JY, Liou SN, Lee GY, Wang JS. Online classifier construction algorithm for human activity detection using a tri-axial accelerometer. Applied Mathematics and Computation 2008; 205(2): 849-860.

[23] Eberhart R, Kennedy J. Particle swarm optimization. In Proceedings of the IEEE international conference on neural networks; 1995; Australia. 1942-1948.

[24] Karaboğa D. Yapay Zeka Optimizasyon Algoritmaları. Nobel Yayın Dağıtım Tic. Ltd. Sti., 2011.

[25] Anguita D, Ghio A, Oneto L, Parra X, Reyes-Ortiz JL. A Public Domain Dataset for Human Activity Recognition Using Smartphones. 21th European Symposium on Artificial Neural Networks, Computational Intelligence and Machine Learning, ESANN 2013; 2013; Belgium.

[26] Jain A, Kanhangad V. Human activity classification in smartphones using accelerometer and gyroscope sensors. IEEE Sensors Journal 2017; 18 (3): 1169-1177. 